\title{
ANÁLISE ERGONÔMICA NA CELESC DISTRIBUIÇÃO S.A. DEPARTAMENTO DE TECNOLOGIA DA INFORMAÇÃO
}

\section{ERGONOMIC ANALYSIS ET THE CELESC DISTRIBUTION S.A. DEPARTMENT OF TECHNOLOGY OF THE INFORMATION}

\author{
Rafael Soares Cardoso ${ }^{1}$; Rosana Rosa Silveira ${ }^{2}$; Ana Maria B Franzoni ${ }^{3}$; Nilo Otani ${ }^{4}$ \\ ${ }^{1}$ Universidade Federal de Santa Catarina - (UFSC) - Florianópolis - Brasil rafaelsoc@gmail.com \\ ${ }^{2}$ Universidade Federal de Santa Catarina - (UFSC) - Florianópolis - Brasil \\ rosanarsil@yahoo.com.br \\ ${ }^{3}$ Universidade Federal de Santa Catarina - (UFSC) - Florianópolis - Brasil \\ afranzoni@hostbr.com.br \\ ${ }^{4}$ Universidade Federal de Santa Catarina - (UFSC) - Florianópolis - Brasil ni_otani@yahoo.com.br
}

\begin{abstract}
Resumo
Esta pesquisa buscou estabelecer a relação entre dois grupos de pessoas dentro de um mesmo setor que é o Departamento de Tecnologia da Informação da Celesc Distribuição S.A, na cidade de Florianópolis-SC, no que tange a ergonomia em escritórios, com enfoque mais preciso em cadeira, mesa e computador. No total, foram pesquisados 48 empregados do referido Departamento. Para a formação dos dois grupos foi feito um sorteio, ficando os 24 inicialmente sorteados no primeiro grupo e os restantes no outro. A diferença entre os dois grupos pesquisados é que no primeiro foi aplicado o questionário de forma direta, sem orientação teórica, e no segundo foi dado um acompanhamento mais próximo por meio de esclarecimento de dúvidas e um informativo com tópicos sobre ergonomia em escritórios antes do preenchimento das respostas. Outro fator importante foi a adaptação do questionário para o segundo grupo de modo a aprimorar a pesquisa. A posição sentada, a dor no corpo, a sobrecarga visual devido ao uso de monitores, a avaliação de componentes do computador, a mesa e o espaço físico de trabalho, estão entre os temas abordados nas questões.
\end{abstract}

Palavras-chave: Ambiente de trabalho; Ergonomia; Pesquisa.

\section{Introdução}

Desde os primórdios do trabalho, passando pela produção artesanal e familiar até as grandes fábricas e indústrias, o trabalho exige dedicação mental e física, sendo o ambiente físico de relevante importância para a realização das atividades.

Dentro desse contexto, o avanço tecnológico tem possibilitado que o trabalho possa ser executado de forma adequada às capacidades e limitações de cada pessoa (VYSKOCILCZAJKOWSKI; GILMORE, 1992). Hoje já é possível se pensar em empresas que sejam viáveis 
economicamente e que não coloquem em risco a saúde do trabalhador devido às atividades que executam. O grande desafio é o de se administrar organizações com este foco e ao mesmo tempo ser competitiva.

Para melhorar a relação entre trabalho e ser humano a ergonomia é estudada e seus conceitos passam a ser aplicados às empresas em geral. A palavra ergonomia tem origem grega, ergon que significa trabalho e nomos, corresponde à legislação, normas. Em resumo, a ergonomia é a análise das atividades desenvolvidas em ambientes impróprios ou mal planejados que podem influenciar no trabalho das pessoas. Seu foco primordial é a atividade de trabalho das pessoas e a busca pela melhoria de suas condições de execução com objetivo de um uso mais adequado na operação de produtos (BLOK; OUWERKERK; VRIES-GUEVER, 1991; CORLETT, 1981).

O estudo da ergonomia representa uma ferramenta fundamental para a análise dos dados obtidos em uma estação de serviço e com isso pode proporcionar a melhor adaptação do trabalho ao homem.

Enquanto prática, a ergonomia é a ocupação de grupos de pesquisa e formação aptos que trabalham em equipes de consultoria e projeto para responder à procura das pessoas no que se refere à atividade de trabalho, da melhor organização e utilização dos recursos disponíveis através da análise dos mesmos. Na realização de suas atividades, o trabalhador pode se deparar com algumas condicionantes do trabalho que influem sobre a sua vida/saúde. Dentre as condicionantes se podem citar o ruído, a iluminação, a higiene e a organização do trabalho. Se o fator iluminação, por exemplo, faltar ou estiver em excesso, poderá afetar o profissional na saúde com as doenças e na vida com as privações conseqüentes das doenças resultantes do trabalho em local não apropriado às atividades. Aí entra a segurança e higiene do trabalho do qual se pode citar a NR-17 que regula as condições de trabalho aos indivíduos.

A NR - 17, que é denominada como Ergonomia, zela de forma jurídica através de normas legais a atividade do ergonomista na empresa. Os aspectos tratados por esta NR são: manuseio de materiais, mobiliário, equipamentos, condições ambientais de trabalho e a sua organização. Nesse artigo serão abordados mais especificamente sobre questões de mobiliário. Em relação à mobília cita Vidal (2002, p. 173), "o mobiliário deve ser adaptado às características antropométricas da população e também a natureza da tarefa." O correto é que o posto de trabalho sirva para o serviço realizado de modo adequado a maioria dos trabalhadores, senão consegue corresponder a todos.

Os conhecimentos obtidos com o estudo da ergonomia em escritórios serão aplicados na presente pesquisa. Nesse sentido, a partir desse enfoque, objetiva-se analisar medidas que possam propor ações corretivas no uso de computadores, mesas e cadeiras do Departamento de Tecnologia da Informação - DPTI da CELESC. 


\section{Procedimentos Metodológicos}

Os procedimentos metodológicos adotados na investigação da presente pesquisa caracterizam-se como sendo: pesquisa exploratória, pesquisa conclusiva do tipo descritiva, amostragem probabilística de técnica aleatória simples, com análise quantitativa. A metodologia inicialmente adotada foi a da pesquisa exploratória, que supri o pesquisador de informações para melhor se trabalhar com o tema. Para isto, é preciso seguir alguns métodos. Reforçando esta afirmação, vale citar o seguinte trecho em relação a este tipo de pesquisa que "[...] utiliza métodos bastante amplos e versáteis. Os métodos empregados compreendem: levantamento em fontes secundárias, levantamentos de experiências, estudos de casos selecionados e observação informal." (MATTAR, 1993, p. 86). Vale ressaltar que este período de início de trabalho compreendeu os meses de novembro e dezembro de 2006.

Após esta etapa nos meses de janeiro, fevereiro e março foram realizadas atividades como a realização de vídeos no local de trabalho, levantamento de dados na empresa, mais consultas a livros e internet, além da elaboração e aplicação dos questionários. Já nessa fase, a pesquisa passou a ser descritiva. O estudo descritivo foi analisado sob ótica quantitativa, isto é, quanto a sua natureza, a pesquisa quantitativa, probabilística do tipo aleatória simples foi escolhida devido à probabilidade de seleção ser igual para todos os elementos. Segundo Malhotra (2001, p. 309), “cada elemento é selecionado independentemente de qualquer outro e a amostra é extraída de um arcabouço amostral por um processo aleatório." Logo, todos os empregados em atividade do Departamento Tecnologia da Informação em março desde ano foram sorteados para compor os 2 grupos de pesquisa. Os 24 primeiros sorteados foram alocados diretamente para o primeiro grupo e os restantes para o segundo grupo.

Com relação ao universo da pesquisa optou-se por 48 empregados em atividade no mês de março no Departamento de Tecnologia da Informação. No entanto, tendo em vista o pequeno número de empregados, decidiu-se pela pesquisa censitária. Entende-se como Pesquisa Censitária aquela que não considera uma amostra, em outras palavras, a pesquisa é aplicada e envolve a população total, e não só uma parte como a pesquisa do tipo amostral.

O método usado para a coleta de dados foi o questionário. Foram utilizados para obtenção de informações teóricas a bibliografia. Por estas fontes de informação, se deu inicio a montagem do questionário que foi aplicado ao primeiro grupo da pesquisa. Para coleta de dados, foram utilizados dois tipos de questionários com 18 questões estruturadas cada. Estes tipos de questionários foram aplicados ao primeiro e segundo grupos da pesquisa. Em relação às questões estruturadas, conforme Malhotra (2001, p. 282) são, "perguntas que pré-especificam o conjunto de respostas alternativas e 
o formato da resposta. Uma pergunta estruturada pode ser de múltipla escolha, dicotômica ou escalonada."

No que se refere à delimitação e limitações, não foi objetivo deste trabalho, obter informações relativas a dados pessoais dos empregados assim como pesquisar funcionários terceirizados e clientes. Pode-se citar como fatores limitadores da pesquisa: a falta de empenho por parte de alguns dos empregados no preenchimento dos questionários e a dificuldade em encontrar alguns destes devido a licenças, férias ou viagens.

\section{A Ergonomia em Escritórios}

Para se reduzir a fadiga, acidentes de trabalho e estresse, o ambiente de trabalho precisa ser seguro, adaptado as diferenças físicas individuais e proporcionar satisfação. Porém, para se ter isso, é necessário que o ambiente de trabalho seja bem planejado e analisado através de um bom projeto.

A ergonomia é necessária para se adaptar o projeto as necessidades dos trabalhadores e estes desempenharem suas funções de forma eficiente. Adaptando o projeto ao trabalho, se tem uma redução em acidentes de trabalho, aumento de produtividade e uma qualidade de vida melhor. Vale citar uma definição de Qualidade de Vida no Trabalho - QVT, que teve início na década de 50 com Eric Trist e colaboradores com objetivo de reunir os elementos: indivíduo, trabalho e organização. Conforme Rodrigues (1991, p.77) a QVT é, “[...] uma abordagem sócio-técnica em relação à organização do trabalho, tendo como base a satisfação do trabalhador no trabalho e em relação a ele."

Porém, devido ao projeto deficiente de grande parte dos postos de trabalho e equipamentos, o indivíduo acaba adquirindo uma postura errada. Algumas conseqüências dessa má postura são o cansaço e dores no corpo. Por isso, um projeto deve ser feito com a visão da empresa como um todo, desde o início até o fim do processo e com isso seus setores e trabalhadores. Um bom projeto tem como resultado um ambiente de trabalho mais agradável. Vale citar Vidal (2002, p. 174) no que tange a condições ambientais, “[...] um meio - ambiente de trabalho onde o trabalho possa vir a ser executado com conforto, segurança e eficiência."

Até o final da década de 70, o trabalhador em ambiente de escritório vivia sua rotina se locomovendo mais como para atender ao telefone, a utilização da máquina de escrever por curto espaço de tempo, arrumar papéis e organizar arquivos. Segundo Grandjean (1998, p. 238), "Estas atividades estão ligadas a uma constante alteração da postura do corpo, de modo que posturas forçadas ou de sobrecarga visual de longa duração não ocorrem.” A chegada em massa dos computadores nos postos de trabalho na década de 80 , fez com que esse cenário mudasse já que o 
trabalhador adquiriu um ritmo de trabalho bem diferente e passou a ficar grande parte do expediente de serviço na mesma posição em frente ao monitor. Nessa passagem de tempo, muitas posturas de trabalho e ambientes não foram adaptados ou corrigidos adequadamente, causando efeitos colaterais pelo corpo como dor nos ombros, braços e cabeça, daí vem a importância da ergonomia no projeto de escritórios.

Basicamente, existem dois tipos de escritórios: o aberto e o tradicional. No primeiro, não se têm paredes fixas até o teto e os setores são separados por divisórias não muito altas, sem portas. Já no tipo de escritório tradicional, segundo Iida (2005, p. 579) “[...] é aquele que tem corredores bem definidos, dando acesso a diversas salas fechadas."

A Celesc Distribuição S.A. se engloba no tipo de escritório aberto, já que seus departamentos e divisões são separados por divisórias e não há portas. Entre as vantagens deste tipo de escritório cita lida (2005, p. 579) “[...] permite uma redução de 40 a 50 \% no espaço necessário, economiza até $95 \%$ nos custos de instalação e modificações de layout e $20 \%$ nos custos de manutenção, e aumenta a produtividade em 10 a $20 \%$ [...]”. A produtividade cresce devido à redução da monotonia, com a mudança de layout com um ambiente mais flexível. Também com as divisórias baixas e não existência de portas facilita as comunicações e com isso a agilidade no serviço.

Alguns pontos negativos também podem ser citados em relação ao tipo de escritório aberto, tais como: excesso de barulho, perda de privacidade e a perda de concentração mais facilmente devido a interferências de outras pessoas.

\subsection{A Mesa e a Cadeira no Trabalho}

É preciso se sentir bem e confortável num escritório, uma vez que se permanece algum tempo no expediente de serviço exercendo as atividades. Esta parte do trabalho será dedicada à sugestão de mesa e cadeira que proporcionem um melhor rendimento e saúde para o trabalhador.

A mesa e a cadeira formam um conjunto integrado, já que para se atingir a postura correta, um depende do outro. A altura da mesa e da cadeira deve ser analisada de forma que a superfície da mesa fique mais próxima possível na altura do cotovelo do indivíduo sentado. Segundo Iida (2005, p. 155) “[...] entre o assento e a mesa deve haver um espaço de pelo menos $20 \mathrm{~cm}$ para acomodar as coxas [...]" Essa distância se justifica devido a maior flexibilidade no movimento durante o trabalho com este espaço.

$\mathrm{Na}$ mesa, o recomendável é que o material frequentemente utilizado fique ao alcance dos braços. Pode-se citar para auxiliar esta afirmativa, as áreas de alcance ótimo e máximo. A área de alcance ótimo, conforme Iida (2005), é a área atingida quando se movimenta os antebraços em 
torno dos cotovelos com os braços para baixo ao lado do tronco. As medidas informadas são um arco com raio de 35 a $45 \mathrm{~cm}$. A área ótima pode ser definida como a área que se pode trabalhar com as duas mãos e é localizada em frente ao corpo, resultado da interseção com os dois arcos.

Já o Grandjean (1998, p. 59) ainda referente a esta figura acima, define "o espaço de preensão corresponde à distância ombro-mão preensil, e o espaço de trabalho corresponde à distância cotovelo-mão preensil." Portanto, neste espaço de preensão, os materiais de trabalho devem estar organizados para manuseio. Este autor cita que sem prejuízos, ocasionalmente, pode fazer movimentos com alcance de 70 a $80 \mathrm{~cm}$. Em relação às dimensões da mesa, existem duas variáveis para medição, que é a sua altura e a superfície onde o indivíduo irá trabalhar. No Departamento de Tecnologia da Informação, que é o setor da empresa que está sendo estudado, não tem mesas reguláveis, só fixas. Na concepção de Iida (2005, p. 145), "Se a mesa tiver uma altura fixa, a cadeira deve ter altura regulável".

$\mathrm{Na}$ análise local foi observado que grande parte das cadeiras é regulável, sendo 68 deste tipo e 52 fixas. No total, se têm 120 cadeiras que são utilizadas entre os empregados, funcionários terceirizados, clientes e para ambientes reservados para reuniões. Deste modo, para as cadeiras fixas e que o trabalhador não consiga colocar os pés no chão, é recomendável o uso de apoio. Para sentido de informação maior foram contabilizadas 55 cadeiras reguláveis apresentam apoio para os braços e 13 cadeiras sem este item.

Segundo Grandjean (1998, p. 49), “[...] altura de mesas de 74 a $78 \mathrm{~cm}$ dão as melhores oportunidades ao empregado para sua adaptação individual.” Isso se aplica melhor quando a cadeira é regulável e se tem apoio para os pés. O que se assemelha a observação de Redgrove citado por Iida $(2005$, p. 145) que "[...] propõe um arranjo com mesa de $74 \mathrm{~cm}$ de altura e cadeiras reguláveis entre 47 e $57 \mathrm{~cm}$, complementado com um estrado, também regulável, para os pés, com 0 a $20 \mathrm{~cm}$ de altura." A aplicação deste estrado seria para pessoas com altura baixa. Veja figura logo em seguida:

Figura 1 - Dimensões recomendadas para alturas de mesas, cadeiras e apoio para os pés

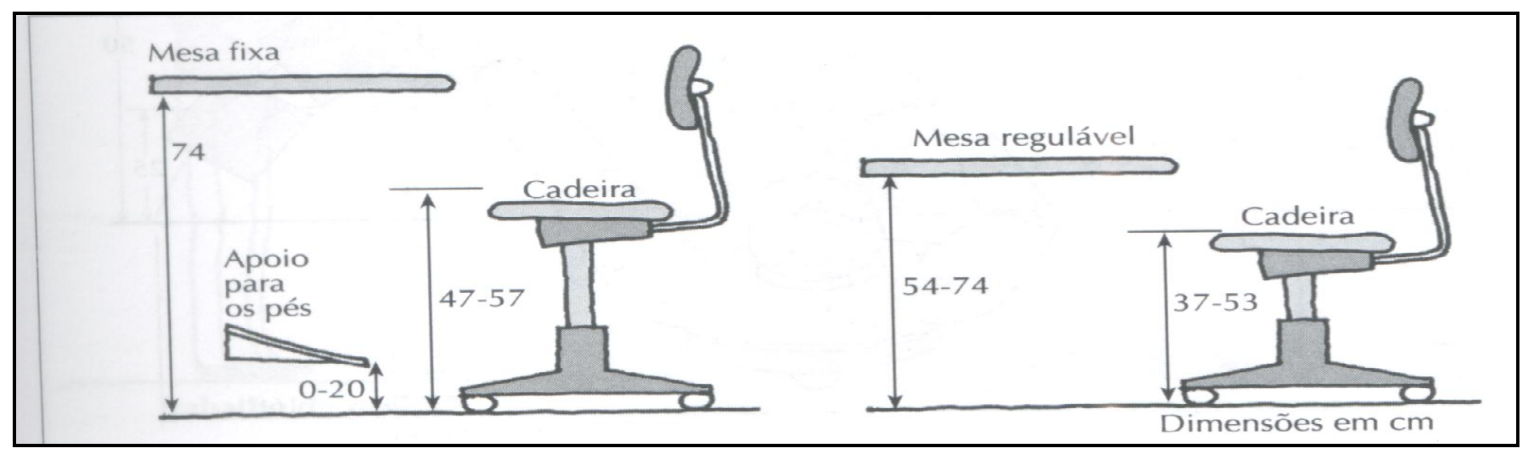

Fonte: Iida (2005, p.145) 
Além da importância de se indicar as medidas das cadeiras, vale ressaltar também o seu material e desenho. Em seu livro, Iida (2005, p. 149) cita que o assento “[...] deve ter característica anti-derrapante e ter a capacidade de dissipar o calor e suor gerado pelo corpo, não sendo recomendados, por conseguinte, plásticos lisos e impermeáveis.” Já o estofamento, deve ter uma base rígida, porém com uma camada de menos densidade na superfície. Isto se deve, porque um estofamento muito duro causa pressão nas tuberosidades isquiáticas (os dois ossos de forma arredondada situados na bacia) o que gera dores das nádegas e fadiga. O estofamento muito macio não permite um equilíbrio do corpo adequado. Iida (2005, p. 149) informa que "[...] um estofamento pouco espesso, de 2 a $3 \mathrm{~cm}$, colocado sobre uma base rígida, que não se afunde com o peso do corpo, ajuda a distribuir a pressão e proporcionar maior estabilidade ao corpo."

Em relação ao desenho de uma cadeira para escritório no que tange ao encosto e assento da cadeira, afirma Iida (2005, p. 154) "[...] pode-se deixar um espaço vazio de 15 a $20 \mathrm{~cm}$ entre o assento e o encosto.” Esse vão de forma côncava é recomendável já que a curvatura da coluna vertical varia entre as pessoas e a protuberância para trás na altura das nádegas quando se fica sentado.

No livro de Grandjean (1998, p. 69), em relação a pesquisas anteriormente realizadas se chega à conclusão de que "[...] os assentos que permitam um eventual recostar do tronco devido ao seu espaldar alto, devem ser preferidos." Isto se deve, a um bom apoio à coluna vertebral lombar, permitindo uma inclinação do tronco tanto para frente como para trás e gerando assim maior conforto. Segundo o mesmo autor citado anteriormente (1998, p. 70), "O encosto deve ter uma altura de 48 a $52 \mathrm{~cm}$ acima do assento (na perpendicular). Uma largura entre 32 e $36 \mathrm{~cm}$ é recomendável." Sobre o assento, o indicado é que tenha de 40 a $50 \mathrm{~cm}$ de largura e entre 38 e $42 \mathrm{~cm}$ de profundidade. Também vale citar que em relação ao espaldar, caso tenha curvatura côncava, que possua um raio entre 40 e $50 \mathrm{~cm}$ e sobre a altura da cadeira que tenha uma graduação de 38 a 54 $\mathrm{cm}$. Portanto, esta é uma sugestão de cadeira projetada ergonomicamente. Além destas medidas e desenho citado, é recomendável que a borda do assento seja de forma frontal arredondada e que seja giratório de maneira a facilitar os movimentos durante a execução do serviço, o que reduz a fadiga do empregado.

\subsection{O Trabalho com Monitores}

O posto de trabalho com monitores faz com que o usuário passe horas com o corpo em movimento mínimo. Este fato se deve ao alto grau de concentração exigido, forçando o indivíduo a permanecer muito tempo na mesma posição e se esta posição de trabalho estiver de forma errada, isso pode ser muito prejudicial ao rendimento e a saúde. 
Entre as conseqüências negativas de um monitor mal utilizado, podem-se citar a fadiga visual e dores musculares. Vale citar, o papel da ergonomia nesse quesito de monitores segundo Grandjean (1998, p. 240), “[...] analisar objetivamente as condições de trabalho e, conforme as possibilidades, determinar linhas mestras para uma ótima concepção dos locais de trabalho com monitores e sua periferia."

Para um posto de trabalho com computadores, as cadeiras segundo Iida (2005, p. 213), “[...] devem ter um encosto com inclinação regulável entre $90^{\circ}$ e $120^{\circ}$." Isto se deve porque facilita a mudança de postura entre a posição ereta (pernas, coxas e tronco fazendo $90^{\circ}$ ) e inclinada (posição parecida de quando se esta sentado no carro, mais relaxada). Está mudança de posição é importante já que diminui o cansaço de ficar muito tempo quase com o corpo parado diante do monitor. Recomenda Grandjean (1998, p. 256), “[...] nos locais de trabalho com monitores deve ser usada uma cadeira com encosto alto."

$\mathrm{Na}$ ergonomia, o trabalho com monitores pode ser dividido em dois grupos: o trabalho de diálogo e a entrada de dados. A diferença entre os dois é que no primeiro, o olhar fica fixo na tela por mais tempo e a troca de olhar acontece menos, já no segundo, o olhar fica menos tempo fixo na tela e a troca de olhar acontece mais vezes. Outra diferença importante citada no livro de Grandjean (1998) é que no trabalho de diálogo, o teclado é utilizado pelas duas mãos com menor número de batidas e já na entrada de dados o trabalho de digitação ocorre frequentemente apenas pela mão direita enquanto a outra mão toca nos documentos.

Em geral quando o monitor é utilizado para trabalho repetitivo e monótono, isso pode gerar baixa satisfação em relação à atividade, o que pode trazer perturbações digestivas e mau-humor. Entre os maiores incômodos com trabalho usando monitor, temos: altura de trabalho não adequada (tela muito próxima ou distante, em posição muito elevada ou baixa), pouca luz para leitura no monitor e claridade direta causando ofuscamento na tela. Em relação a este assunto, afirma Grandjean (1998, p. 245) “[...] em muitas pesquisas de campo constatamos que os reflexos eram considerados a mais desagradável manifestação que acompanha o trabalho em monitores."

Segundo Iida (2005, p. 217) em relação à redução do ofuscamento e reflexos no posto de trabalho, “[...] utilizando-se fontes de luz difusa e indireta, eliminando-se superfícies refletoras e colocando as luminárias de modo que a luz incidente no posto de trabalho tenha ângulos menores que $45^{\circ}$ em relação à vertical.” O mesmo autor também dá a sugestão de alterar a posição da tela do monitor em relação às fontes de luz, como lâmpadas e janelas. Veja na página seguinte a figura 2: 
Figura 2 - Posicionamento das luminárias e monitor

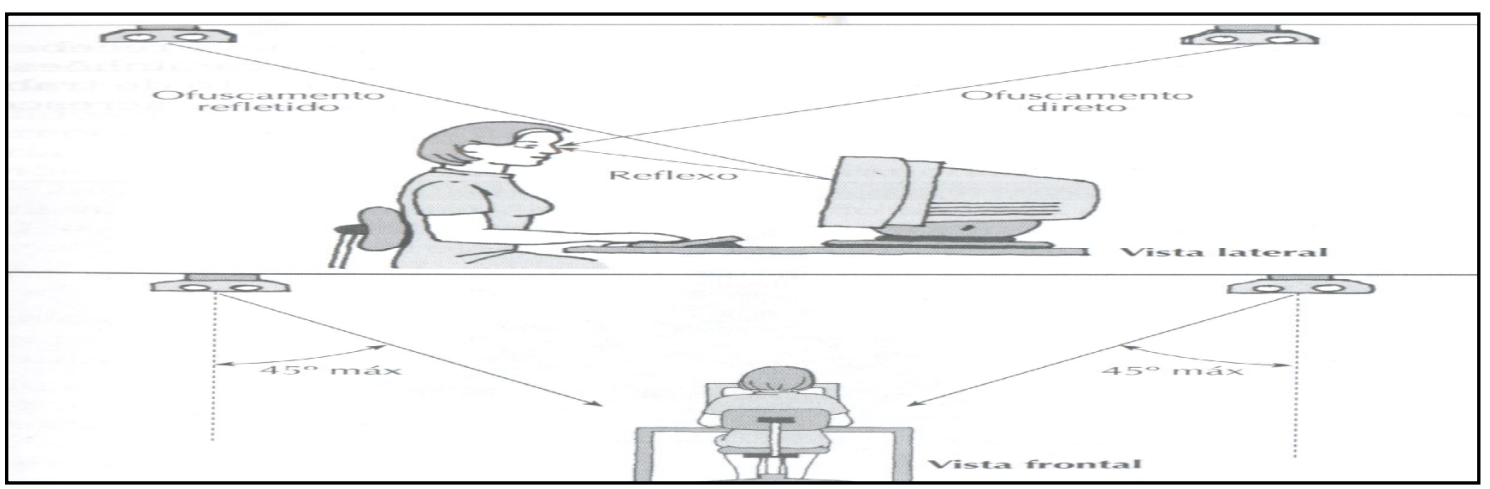

Fonte: Iida, 2005, p.217

No trabalhado com monitores, segundo Carter e Banister citado por Iida (2005, p. 215), a altura entre o piso e centro da tela tem que ficar entre 90 e $115 \mathrm{~cm}$. Em relação a distância visual, o recomendado é ficar de 41 a $93 \mathrm{~cm}$ dos olhos até a tela. Já referente ao ângulo visual, atingir entre 0 e $30^{\circ}$ do nível dos olhos na posição horizontal para baixo. Para se alcançar este ângulo no campo visual pode-se usar um acessório para elevar a altura do monitor.

Além da tela do monitor, outro acessório importante é o teclado. Este deve ter teclas leves para tocar e um som mínimo. Ao digitar, o recomendável é estar com teclado a sua frente com o mouse localizado a sua direita ou esquerda. Na mesa, devem estar na mesma altura o mouse e teclado, e estes devem ficar aproximadamente à altura do cotovelo (observar a figura acima). A posição correta é uma linha reta entre o cotovelo e o pulso no momento do uso do mouse e teclado.

\section{Análise Global dos Dados da Pesquisa}

Nesta parte do trabalho, após a interpretação dos dados coletados no primeiro e segundo grupo, serão analisadas as informações por questão comparando os dois grupos da pesquisa. No total foram pesquisados 48 empregados. O objetivo desta subunidade é fazer uma análise global e com os dados obtidos buscar sugestões de melhoria. Na descrição de algumas informações pode se chegar a um valor maior que 48 devido aos empregados que marcaram mais de uma opção.

Referente à primeira questão aplicada nos questionários, a diferença está na maior faixa etária atingida. No primeiro grupo predominou a faixa etária entre 40 e 49, enquanto que no segundo a de entre 30 e 39 anos. Somando os grupos, temos 24 empregados entre 40 e 49 e, 10 entre 30 e 39 anos. Na faixa entre 20 e 29 anos, 9 empregados. Apresentando 50 anos ou mais, 5 empregados. Em ambos, nenhum empregado com idade menor que 20 anos.

Sobre a posição sentada, a maioria dos empregados do primeiro grupo informou adotar a posição em que fica sentado em toda a cadeira. Porém, no segundo grupo, outro item atingiu a maior parcela, o de sentar com os braços apoiados na mesa. Relacionado este dois itens, no primeiro 
grupo, só 1 empregado informou adotar as duas posturas e 2 empregados no segundo grupo. No total, somando os grupos, 21 empregados sentam em toda a cadeira enquanto que 19 ficam com os braços apoiados na mesa.

Em relação à terceira questão do questionário aplicada aos dois grupos, que é a de informar a parte do corpo onde sente dor ao sentar, no primeiro grupo voltaram 5 questionários em branco em relação a essa questão. Para o questionário aplicado ao segundo grupo foi posta mais uma alternativa, a de não sentir dores, todos os questionários voltaram preenchidos. No primeiro grupo, a maior parcela dos pesquisados, 17 empregados, responderam que sentem dores nas costas enquanto que no segundo grupo, 11 empregados. Neste último grupo citado, a maioria marcou a alternativa de sentir dor na nuca e ombros. No somatório dos grupos, 28 empregados sentem dores nas costas e 21 empregados na nuca e ombros.

A questão seguinte foi referente ao estresse no trabalho com monitores. No primeiro grupo, 13 empregados relataram ter prejuízo de humor. Neste grupo, voltaram 3 questionários em branco quanto a essa questão. Já no segundo grupo a maioria, totalizando a quantidade de 13 empregados, informaram não ter nenhum tipo de problema em relação ao estresse com monitores. Este último item citado foi adicionado ao questionário aplicado no segundo grupo, portanto para o primeiro grupo não tinha esta opção. No total dos dois grupos, 19 empregados informaram ter prejuízos de humor e empatados com 13 empregados cada, os itens de baixa satisfação no trabalho e os que não tem problema de estresse com monitores.

No que tange aos sintomas devido à sobrecarga visual derivada ao uso de monitores no trabalho, foram atingidos dados muito importantes. Na análise dos resultados do primeiro grupo foi verificado que a maior parcela dos empregados sente dores de cabeça e tem sensações doloridas de irritação nos olhos. Resultado semelhante foi obtido no segundo grupo. No somatório dos grupos, 21 empregados sentem ardência nos olhos e 19 empregados sentem dores de cabeça. Em menor número os que apresentam visão dupla, totalizando 7 empregados. Duas opções foram adicionadas ao segundo grupo, a de "outro" e "não tive ou apresento esses sintomas". No primeiro grupo, 2 questionários voltaram sem respostas.

Ao trabalhar com monitor, o empregado fica exposto a uma série de fatores. Pela maior parte dos empregados do primeiro grupo, nada foi percebido. Em relação ao segundo grupo, os reflexos sobre a superfície de vidro do monitor são nítidos. No total dos grupos, 19 empregados relataram sentir os reflexos na tela enquanto que 13 nada perceberam. Uma observação relevante é que esses 13 empregados são somente do primeiro grupo, pois no outro grupo pesquisado, não teve nenhum preenchimento neste item. Vale destacar a diferença de aplicação nos questionários de um grupo para o outro (mais detalhes na metodologia deste trabalho), no segundo grupo teve uma 
informação maior através de informativo e esclarecimentos diretamente com os pesquisadores. Voltaram sem preenchimento, 2 questionários do primeiro grupo.

$\mathrm{Na}$ avaliação do teclado utilizado, a maior parte dos empregados forneceu uma opinião positiva. No segundo grupo, a maioria dos pesquisados informou que o teclado é confortável. No total, 19 empregados passaram esta informação. Vale ressaltar que o item "confortável" foi adicionado como opção no questionário aplicado ao segundo grupo. Porém, 12 empregados relataram não saber como avaliar o teclado. Destes, 11 fazem parte do primeiro grupo, no qual não houve qualquer esclarecimento e nem informativo. Para 9 empregados, o teclado utilizado causa dores nos pulsos. Nessa questão, voltaram em branco do primeiro grupo 4 questionários.

Depois da avaliação do teclado, foi perguntado em relação ao mouse. No primeiro grupo, 12 empregados informaram sentir dor nos pulsos, enquanto que no segundo grupo, foram 6 empregados. Nesse primeiro grupo da pesquisa, voltam 4 questionários com está questão em branco. Para o questionário aplicado ao segundo grupo, foram postas mais duas alternativas que são: "acumula sujeira" e "confortável". Estes itens adicionados foram os que conseguiram mais preenchimentos neste último grupo pesquisado. A opção "confortável” totalizou 12 empregados e "acumula sujeira" com 8. Um dado importante é que no primeiro grupo, 8 empregados não sabiam como responder enquanto que no outro grupo nenhum preencheu este item. Todos os questionários deste grupo voltaram marcados.

$\mathrm{Na}$ questão seguinte nos questionários aplicados aos grupos, foi perguntado sobre a avaliação do mouse pad. Um bom resultado foi atingido, com a maioria das respostas dos dois grupos foi marcada a opção "confortável” com 11 empregados em cada grupo, totalizando 22 empregados. No primeiro grupo, 2 questionários não tiveram resposta nesta questão enquanto que no outro grupo todos foram respondidos. Porém, 16 empregados avaliam o mouse pad como desconfortável, tendo 8 empregados para cada grupo. Para o questionário aplicado ao segundo grupo, foi adicionada uma opção para quem não utiliza mouse pad. Este item citado atingiu 5 preenchimentos.

Para saber se a mesa, mouse e teclado estão na mesma altura foi elaborada essa questão. Foi obtido um excelente resultado, no total dos grupos, 42 empregados, sendo 21 de cada grupo pesquisado, respondeu afirmativamente que os elementos citados estão no mesmo nível. Só 1 empregado do primeiro grupo respondeu que o mouse fica abaixo do teclado e no segundo grupo ninguém relatou este fato. Na situação em que o teclado está abaixo do mouse, na soma dos grupos, 5 empregados informaram estar nessa situação.

No que tange a altura do cotovelo ao clicar e digitar em relação ao mouse e o teclado, somando os 2 grupos, 35 empregados informaram positivamente que os elementos citados se encontram a mesma altura do cotovelo. Destes empregados, 19 do primeiro grupo e 16 do segundo. 
No primeiro grupo pesquisado, só 1 questionário voltou em branco. Parcela considerável dos empregados informaram negativamente a esta questão, totalizando 4 empregados do primeiro grupo e 8 do segundo. Para o questionário aplicado ao último grupo, foi elaborada uma terceira alternativa que relata sobre o desconhecimento da informação de saber da altura do cotovelo relacionando ao mouse e teclado. Para este item, não foi obtido nenhum preenchimento.

Referente à mesa, foi perguntado mediante os questionários, o que os empregados percebem de quando da sua utilização. Em ambos os grupos, a maior parte dos empregados marcou a opção de que se tem pouco espaço para colocação de documentos e materiais na mesa. O total obtido para este item citado foi de 22 empregados. No primeiro grupo, a segunda alternativa mais marcada foi a de que a tela do computador fica muito próxima dos olhos. Já no outro grupo, o segundo item mais preenchido foi o monitor se encontra muito alto ou baixo em relação à visão. No somatório dos grupos, a segunda opção mais marcada foi da proximidade da tela em relação aos olhos, totalizando 12 empregados. No questionário aplicado ao primeiro grupo, 4 voltaram em branco. Para o questionário do segundo grupo foram adicionadas mais quatro alternativas sendo estas: "monitor (es) muito baixo (s) ou muito alto (s) em relação a sua visão", "acumula sujeira", "mesa pequena" e “não sei”. Das alternativas adicionadas a mais preenchida foi o da altura do muito baixo ou alto em relação a visão, totalizou 9 empregados.

$\mathrm{Na}$ questão seguinte do questionário, foi perguntado se o material de trabalho na mesa fica ao alcance dos braços. A proporção das respostas foi equilibrada entre os grupos. No primeiro grupo, 22 empregados e no outro grupo 21 responderam "sim", totalizando 43 empregados. Já os que responderam "não" somam 5 pesquisados, sendo 2 do primeiro grupo e 3 do segundo. Em ambos os grupos todos responderam a esta questão.

Referente ao espaço físico da mesa para o computador e materiais de serviço foi perguntado aos empregados sobre o que eles acham, se necessitam de mesa maior ou se está bom como está. No total, 33 empregados sentem a necessidade de mesa maior. Destes 18 fazem parte do primeiro grupo e 15 do segundo. Já em relação aos que estão satisfeitos com a situação atual, totalizaram 11 empregados. Dos citados, 3 fazem parte do primeiro grupo e 8 do outro grupo. Os que informaram não saber como responder, resultaram 3 no primeiro grupo e só 1 no segundo.

Para se saber quantos empregados do Departamento de Tecnologia da Informação já estiveram afastados do serviço por Distúrbios Osteomusculares Relacionados ao Trabalho (DORT) foi formulada esta questão. O resultado obtido positivo. No total dos 48 empregados pesquisados, somando os dois grupos, 6 informaram já ter tido este problema. Destes, 5 são do primeiro grupo. Dos que não tiveram, 23 são do segundo grupo. Importante mencionar que nenhum empregado informou não saber se já tinha tido DORT. 
Sobre o espaço físico foi perguntado aos empregados se este é proporcional aos serviços executados. No total, somando os grupos, 32 empregados informaram que o espaço físico disponível para o seu trabalho é suficiente. Destes, 14 são do primeiro grupo e os restantes do segundo. Já os que tiveram opinião contrária, relatando que o espaço não é suficiente e que isso gera erro de postura, totalizaram 15 empregados. O primeiro grupo em relação ao outro, foi o que mais marcou neste item que ficou de 9 a 6 respectivamente. Só 1 empregado informou não saber se o espaço físico é suficiente as suas atividades, este é do primeiro grupo. Para o segundo grupo ninguém respondeu este item de não saber.

A fim de gerar maior conforto para os empregados, foi perguntado o que poderia ser alterado ou ajustado no ambiente de serviço. O item mais preenchido pelos empregados nesta questão foi a de que se deveria alterar o desenho da mesa. Somando os grupos, este item obteve 28 empregados. Destes, 16 são do primeiro grupo. A segunda alternativa mais marcada foi a de é necessário ajustar a distância entre os componentes do computador, totalizando 17 empregados. Desse resultado, 10 pertencem ao segundo grupo. Este mesmo número foi obtido no item "outro", somando os dois grupos.

A última questão do questionário teve como objetivo descobrir quantos empregados já tiveram algum tipo de lesão corporal devido à situação de ter pouco espaço para se locomover. Os empregados que já tiveram algum tipo de lesão, totalizaram 15, somando os dois grupos. Destes, 10 no segundo grupo. Porém, a maioria dos pesquisados, no total de 33 empregados, informaram não ter sofrido nenhuma lesão. Destes, 19 são do primeiro grupo. Do primeiro para o segundo grupo, o número de respostas positivas a ter sofrido lesão aumentou enquanto que para o outro item diminuiu.

\section{Considerações Finais}

Nesta parte final do trabalho, as idéias expostas serão elencadas inicialmente prestigiando-se os pontos positivos encontrados e depois suas deficiências. Enfim, o que precisa ser mudado e aplicado visando proporcionar maior bem estar no trabalho, ou seja, ressaltando-se o que o Departamento pesquisado deve dar prioridade.

Vários pontos muito positivos foram descobertos através das informações colhidas pela maioria dos questionários. Pode-se citar sobre o material que fica ao alcance dos braços enquanto são geradas as atividades para 89,6 \% dos empregados. Os que afirmaram que a mesa, o mouse e teclado estão na mesma altura e os que não tiveram DORT, totalizaram 87,5 \% cada. Em relação à altura do cotovelo enquanto as mãos utilizam o mouse e o teclado, 74,47\% dos pesquisados informaram que cotovelo fica na mesma altura dos hardwares citados. No ambiente de trabalho, 
outra boa notícia refere-se que $68,75 \%$ dos participantes informaram não ter sofrido nenhum tipo de lesão corporal e 66,66 \% estão satisfeitos com o espaço físico onde exercem suas atividades.

Em menor proporção, mas também considerados como resultados satisfatórios, foi com relação a avaliação dos teclados e mouse pads utilizados. O teclado foi considerado como confortável por $43,18 \%$ do total. Muito provável este valor poderia ter sido maior, pois no questionário aplicado ao primeiro grupo não tinha esta alternativa e neste o mais preenchido foi a alternativa "não sei". Outro item que também foi avaliado como confortável foi o mouse pad, que atingiu 47,83 \% do total. Porém 34,78 \% tiveram opinião contrária e afirmaram que o mouse pad é desconfortável.

$\mathrm{Na}$ avaliação dos questionários foi percebido que o Departamento de Tecnologia da Informação deve dar prioridade no ajuste e adaptação de alguns itens em seu ambiente físico de trabalho. Nas linhas seguintes serão descritos pontos que poderão ser mais bem planejados e trabalhados.

$\mathrm{Na}$ questão contida no questionário que se refere a dor no corpo quando se está sentado, $65,12 \%$ dos empregados informaram sentir dor nas costas e 48,84 \% na nuca e ombros. Recomenda-se, a utilização de cadeira que proporcione espaço entre seu assento e mesa para comportar as coxas e facilitar o movimento. Recomenda-se o uso de apoio para os pés quando o empregado estiver sentado e não conseguir pôr os pés no chão, dessa forma, não forçará a posição de ficar sentado na ponta da cadeira. Embora a maior parte das cadeiras do DPTI seja regulável, o melhor seria que todas as cadeiras fossem desse tipo. Vale ressaltar outras características importantes para uma boa cadeira como um estofamento de pouca espessura, em outras palavras, ter um pequeno vão entre o encosto e o assento, encosto mais alto e assentos que facilitem o recostar do tronco.

Já no que diz respeito com relação à sobrecarga visual devido ao uso de monitores, a pesquisa indicou um aspecto negativo. Em outros termos, do total, 45,65 \% dos empregados relataram que sentem ardência nos olhos e 41,30 \% que têm dores de cabeça. Isto pode ocorrer devido a grande proximidade dos olhos em relação à tela, fazendo com que a vista fique cansada. No trabalho com monitores, como o movimento do corpo é mínimo, isso pode trazer dores musculares e desconforto. Ainda em relação aos monitores, outro dado relevante obtido. Os empregados que informaram ter prejuízo de humor totalizaram 42,22 \% e dos que relataram perceber a redução dos reflexos e ofuscamento sobre a superfície da tela, o resultado foi de 41,30 \%. A simples alteração da posição da fonte luz em relação ao monitor ou vice-versa, já elimina ou reduz sensivelmente este problema.

Outro ponto importante a destacar é a necessidade de mesa maior que suporte o computador e os materiais de trabalho. Este item foi apontado, totalizando 68,75 \% dos empregados 
pesquisados. Em observação no ambiente de serviço foi visto que como os materiais empregados são muitos, se utiliza uma segunda mesa para o mesmo funcionário. Geralmente em uma das mesas localizam-se o computador e o telefone e nas demais, os materiais de trabalho e até outro computador em alguns casos. Diante do exposto, a sugestão é a adoção de mesa única e maior; além disso, recomendam-se nas suas extremidades pontas arredondadas para evitar lesões. Também é oportuna uma mesa que permita maior locomoção juntamente com uma cadeira regulável, diminuindo assim o tempo estático do corpo numa mesma posição durante muito tempo. A aplicação desse tipo de mesa poderá trazer redução de dores musculares e da monotonia no serviço.

Concluindo-se, o Departamento de Tecnologia da Informação deve focar a atenção a todos os detalhes referendados pela pesquisa a fim de possibilitar um ambiente mais favorável à saúde do trabalhador. Vale destacar além destes pontos citados, a importância da informação e esclarecimentos maiores quanto à ergonomia por intermédio da organização de palestras e seminários no Departamento. A confecção de informativos bimestrais ou até mensais também vale como sugestão.

\begin{abstract}
This research aimed at establishing a relation between two groups from the same sector which is the Information Technology Department os Celesc Distribution S.A. as far as office Ergonomy is concerned, focusing mainly on chair, desk and computer. In the total, 48 employees from the department previously mentioned have been part of the research. There has been a raffle to form 2 groups, being the 24 initially raffled employees placed in group 1 and the others left in group 2 . The difference between the two groups is that group 1 has been given a plain form, without any theoretical guidance, whereas group 2 has been provided with vital assistance through resolving doubts along with a source of information within topics about office Ergonomy before the fulfilment of the answers. Another important factor was the questionnaire adaptation for group 2, leading to the improvement of the research itself. The position of the body while sitting, the painful body, the sight overload due to the use of the computer monitor, the evaluation of computer components, the desk and the area of work are among the selected themes in the questionnaire. The outcome of the research reveals conclusions that can be used to understand that the guidance related to Ergonomy and the access to information in the working environment can positively influence on the life of beings.
\end{abstract}

Key-words: Working environment. Ergonomy. Research.

\title{
Referências
}

BLOK, A. J.; OUWERKERK, R. J. van; VRIES-GUEVER, A. H. G. de. Analysing combined effects of task demands: the broad ergonomic approach. Taylor and Francis, v.1, 1991, p.448-339.

CORLETT, E. N. Pain, posture and performance. In: E. N. Corlett and J. Richardson (ed). Stress, work design and Productivity. London: 1981, p.27-42.

GRANDJEAN, Etienne. Manual de ergonomia: adaptando o trabalho ao homem. Porto Alegre: Bookman, 1998. 
IIDA, Itiro. Ergonomia: projeto e produção. 2.ed. rev. e ampl. São Paulo: Edgard Blucher, 2005.

MALHOTRA, Naresh K. Pesquisa de marketing: uma orientação aplicada. 3. ed. Porto Alegre: Bookman, 2001.

MATTAR, Fauze Najib,. Pesquisa de marketing: metodologia, planejamento, execução, analise. São Paulo: Atlas, 1993. v. 2.

RODRIGUES, Marcus Vinicius Carvalho. Qualidade de vida no trabalho: evolução e análise no nível gerencial. Fortaleza: UNIFOR, 1991.

VIDAL, Mário César. Ergonomia na empresa: útil, prática e aplicada. 2 ed. Rio de Janeiro: Editora Virtual Científica, 2002.

VYSKOCIL-CZAJKOWSKI, T. L.; GILMORE, S. A. Job satisfaction of selected institutional foodservice supervisors. Journal of Foodservice Systems, n. 7, 1992, p.29-42.

Nome completo: Rafael Soares Cardoso

Filiação institucional: Universidade Federal de Santa Catarina

Departamento: Centro Sócio-Econômico

Função ou cargo ocupado: Estudante de Pós-Graduação

Endereço completo para correspondência: Av. Buriti 259, Itacorubi, Florianópolis, Santa Catarina, Brasil, CEP: 88034-500

Telefones para contato: (48) 3238-1823/(48) 9937-3832

e-mail:rafaelsoc@gmail.com

Nome completo: Rosana Rosa Silveira

Filiação institucional: Universidade Federal de Santa Catarina

Departamento: Engenharia do Conhecimento

Função ou cargo ocupado: Doutoranda do EGC/UFSC

Endereço completo para correspondência: Rua Demétrio Ribeiro, 106 apto 811, Centro, Florianópolis, Santa Catarina, Brasil, CEP: 88020-700

Telefones para contato: (48) 3028-1426/(48) 9902-4454

e-mail:rosanarsil@yahoo.com.br

Nome completo: Ana Maria Bencciveni Franzoni

Filiação institucional: Universidade Federal de Santa Catarina

Departamento: Engenharia do Conhecimento

Função ou cargo ocupado: Professora do EGC/UFSC

Endereço completo para correspondência: Rod. Amaro Antonio Vieira, 1866 apto 606, Itacorubi, Florianópolis, Santa Catarina, Brasil, CEP: 88034-101 
Telefones para contato: (48) 3233-2383/(48) 9972-1018

e-mail:afranzoni@hostbr.com.br

Nome completo: Nilo Otani

Filiação institucional: Universidade Federal de Santa Catarina

Departamento: Engenharia do Conhecimento

Função ou cargo ocupado: Doutorando do EGC/UFSC

Endereço completo para correspondência: Rua Afonso Pena 494, apto 603, Estreito, Florianópolis, Santa Catarina, Brasil, CEP: 88070-650

Telefones para contato: (48) 3244-7991/(48) 9167-9077

e-mail:ni_otani@yahoo.com.br 